\title{
Animal models of myasthenia gravis: utility and limitations
}

This article was published in the following Dove Press journal:

International Journal of General Medicine

4 March 2016

Number of times this article has been viewed

\section{Renato Mantegazza \\ Chiara Cordiglieri \\ Alessandra Consonni \\ Fulvio Baggi}

Neurology IV Unit, Neuroimmunology and Neuromuscular Disorders, Foundation IRCCS Neurological Institute "Carlo Besta", Milan, Italy
Correspondence: Renato Mantegazza Neurology IV Unit, Neuroimmunology and Neuromuscular Disorders, Foundation IRCCS Neurological Institute "Carlo Besta", Via Celoria II, 20I33 Milan, Italy

Tel +3902 23942255

Fax +39027063 3874

Email rmantegazza@istituto-besta.it
Abstract: Myasthenia gravis (MG) is a chronic autoimmune disease caused by the immune attack of the neuromuscular junction. Antibodies directed against the acetylcholine receptor (AChR) induce receptor degradation, complement cascade activation, and postsynaptic membrane destruction, resulting in functional reduction in AChR availability. Besides anti-AChR antibodies, other autoantibodies are known to play pathogenic roles in MG. The experimental autoimmune MG (EAMG) models have been of great help over the years in understanding the pathophysiological role of specific autoantibodies and T helper lymphocytes and in suggesting new therapies for prevention and modulation of the ongoing disease. EAMG can be induced in mice and rats of susceptible strains that show clinical symptoms mimicking the human disease. EAMG models are helpful for studying both the muscle and the immune compartments to evaluate new treatment perspectives. In this review, we concentrate on recent findings on EAMG models, focusing on their utility and limitations.

Keywords: myasthenia gravis, autoimmunity, neuroimmunology, AChR

\section{Myasthenia gravis}

Acquired myasthenia gravis (MG) is a B-cell-mediated T-cell-dependent autoimmune disease, which is characterized by impairment of the neuromuscular junction (NMJ) transmission and caused by specific autoantibodies (auto-Abs) directed against the acetylcholine receptor (AChR) on the postsynaptic membrane of skeletal muscle cells. ${ }^{1-3}$ The majority of AChR antibodies recognize an extracellular domain of the receptor, defined as main immunogenic region, localized between residues 67 and 76 of the $\alpha$-subunit of the receptor. ${ }^{4}$ The development of anti-AChR auto-Abs is apparently due to the breakdown of self-tolerance in the thymus, ${ }^{5-7}$ with activation of AChR-specific $\mathrm{CD}^{+} \mathrm{T}$ helper (Th) cells and production of proinflammatory cytokines, leading to the synthesis of high-affinity antibodies ${ }^{8,9}$ and chemokines contributing to autoimmunity maintenance..$^{10} \mathrm{MG}$ responds to the clinical criteria of antibodymediated autoimmune diseases, ${ }^{11}$ implying the presence of auto-Abs in patients, ${ }^{1,12,13}$ which specifically interact with the target antigen forming immune complexes ${ }^{2,14}$ and induce an experimental model, when injected in recipient animals, reproducing the feature of the disease (passive transfer) ${ }^{15,16}$ Other criteria imply that the immunization with the specific antigen produces an experimental model that is clinically similar to the disease ${ }^{17}$ and that the reduction in circulating antibody levels ameliorates the disease. ${ }^{18,19} \mathrm{AChR}$-specific auto-Abs induce complement activation and damage of the NMJ with increased degradation of AChR. The direct binding of auto-Abs (IgG1 and 
IgG3 subtypes) activates the complement cascade, leading to the formation of the membrane attack complex (MAC) and consequently to the lysis of the muscle cell. ${ }^{14}$ The destruction of the postsynaptic membrane results in a morphological alteration, with decreased number of functional AChRs and sodium channels. ${ }^{20}$ The formation of immune complexes induces endocytosis-mediated internalization of AChR, which is not compensated by ex novo synthesis, and increases lysosomal degradation of AChR, reducing its availability on the postsynaptic membrane. ${ }^{14,21}$ Further impairment of AChR function can also be derived from the physical interaction of a subset of polyclonal anti-AChR auto-Abs to the specific acetylcholine binding sites on the receptor. ${ }^{22}$

\section{Experimental autoimmune myasthenia gravis}

The first report on an experimental model of MG was published $>30$ years ago, ${ }^{17}$ showing that rabbits immunized with AChR, purified from the Electrophorus electricus electric organ, developed MG-like symptoms. Later on, many animal studies confirmed that an autoimmune response was occurring in MG patients against muscle AChR and that anti-AChR antibodies were responsible for the structural and functional damage of the NMJ. Over the years, experimental autoimmune MG (EAMG) has represented an excellent model to investigate the pathogenic mechanisms underlying the human disease and to evaluate the efficacy of new immunotherapies. ${ }^{23}$

MG and its animal models share several immunopathological features ${ }^{23}$ such as the presence of anti-AChR antibodies in serum, IgGs and complement component deposition at the NMJ, major histocompatibility complex class II-restricted presentation of AChR epitopes, and involvement of Th cells in the production of B-cell antibody, ${ }^{24}$ and several clinical features, such as muscle weakness and fatigability, decremented response after repetitive nerve stimulation, increased curare sensitivity, and temporary improvement of muscle strength following treatment with anticholinesterase drugs (Table 1). ${ }^{24}$

Although EAMG can be induced in various animal species, most of the experimental models are established in rats and mice, mainly due to the high incidence of clinical EAMG signs. ${ }^{25}$ The course of EAMG is evaluated by monitoring the loss of body weight and muscular strength of the immunized animals. Myasthenic symptoms, assessed after exercise, include tremor, hunched posture, muscle weakness, and fatigue and are given in detail in Table 2. In susceptible rat strains, EAMG is induced by active immunization with Torpedo californica AChR (TAChR) ${ }^{25}$ or with
Table I Immunopathological similarities and differences between MG and its experimental model

\begin{tabular}{ll}
\hline Similarities & Differences \\
\hline $\begin{array}{l}\text { Presence of anti-AChR antibodies } \\
\text { in serum }\end{array}$ & $\begin{array}{l}\text { Disease does not arise } \\
\text { spontaneously in experimental } \\
\text { animals; need for induction factors } \\
\text { Deposits of IgGs and complement } \\
\text { Involvement of the thymus } \\
\text { (present in MG, absent in EAMG) }\end{array}$ \\
$\begin{array}{l}\text { junction } \\
\text { Loss of muscle AChR }\end{array}$ & $\begin{array}{l}\text { Thymic alterations are absent in } \\
\text { presentation of AChR epitopes } \\
\text { Involvement of T helper cells in } \\
\text { B-cell antibody production }\end{array}$ \\
\hline
\end{tabular}

Abbreviations: AChR, acetylcholine receptor; MG, myasthenia gravis; EAMG, experimental autoimmune myasthenia gravis; MHC, major histocompatibility complex.

a rat $\mathrm{AChR}$ epitope capable of breaking immunological tolerance (amino acids [aa] 97-116 of the $\alpha$-subunit). ${ }^{26,27}$ EAMG can also be induced by passive transfer of anti-AChR antibodies, ${ }^{1,4}$ which is the simplest protocol for studying the pathogenic effects of auto-Abs in vivo.

\section{Active EAMG}

Mice would represent the ideal model for the development of the experimental disease due to the availability of transgenic, knockout, and mutant mice that are optimal for the investigation of the biological mechanisms at the basis of MG pathogenesis. ${ }^{24,28}$ Indeed, EAMG has been intensively studied in mice to better understand the factors that are involved in the disease pathogenesis and to investigate their potential modulation and regulation. Highly susceptible murine strains are $\mathrm{C} 57 \mathrm{Bl} / 6$, SJL, and AKR, where 50\%-70\% of animals developed myasthenic symptoms induced by TAChR immunization, which are different from the poorly susceptible BALB/c and SWR strains. ${ }^{28,29}$ EAMG in the mouse is routinely induced by immunization with purified AChR (20 g) in complete Freund's adjuvant (CFA) followed by two or three boosts with AChR $(20 \mu \mathrm{g})$ in incomplete Freund's adjuvant. This procedure triggers the production of antibodies to both foreign AChR and self-AChR, ${ }^{25,30}$

Table 2 Clinical evaluation of EAMG symptoms

\begin{tabular}{ll}
\hline Clinical score & Symptoms \\
\hline Grade 0 & Normal strength and no fatigability \\
Grade I & Mildly decreased activity and weak grip or cry \\
Grade 2 & Clinical signs present before exercise \\
Grade 3 & Severe clinical signs at rest, no grip, moribund \\
Grade 4 & Death \\
\hline
\end{tabular}

Abbreviation: EAMG, experimental autoimmune myasthenia gravis. 
and myasthenic symptoms typically appear 7-14 days after the last injection. ${ }^{24,28}$ Due to the several immunization boosts required to induce this model, it is relatively difficult to define the appropriate time windows for preventive and/or therapeutic approaches in mice.

Various inbred rat strains have been tested for the induction of active EAMG via immunization with TAChR, with more severe clinical features compared with those observed in murine models. The strain most employed is the Lewis rat, which exhibits clinical manifestations most similar to those of human $\mathrm{MG} .{ }^{31}$ EAMG in Lewis rats is generally induced via single immunization with purified AChR $(20 \mu \mathrm{g})$ in CFA, prompting the production of antibodies to foreign $\mathrm{AChR}$, which similar to the mouse model are able to cross-react with the self-AChR. ${ }^{25,30}$ Two different disease phases can be clinically distinguished. The first acute transient phase begins $\sim 7$ days postimmunization and is characterized by the synthesis of antiAChR antibodies (IgM type), which leads to complement depositions on muscle membrane, extensive phagocytic invasion at the NMJ, and destruction of the postsynaptic membrane. The cellular invasion decreases the AChR content of a rapid muscle, which is followed (after 2-3 days) by an abnormal increase in the AChR content likely due to the formation of extrajunctional $\mathrm{AChR} .{ }^{30}$ The second progressive chronic phase begins $\sim 28$ days postimmunization $^{25}$ and is characterized by the production of a larger amount of antibodies (IgG type) and complement deposition at the postsynaptic membrane, which thus appears flat, due to lack in junctional folds. In this phase, there are no phagocytic cells, and the reduction in skeletal muscle AChR content is such that it is reduced to one-third compared with that of healthy animals. Importantly, this phase reflects the clinical course of the human disease.

In the rat, it was proven that active EAMG can also be induced via immunization with a synthetic peptide, corresponding to the immunogenic region 97-116 of rat AChR $\alpha$-subunit (R97-116) in CFA (50 $\mu$ g of peptide), followed by a second immunization boost of R97-116 (50 $\mu \mathrm{g})$ in incomplete Freund's adjuvant 30 days after the first immunization. ${ }^{26}$ The onset of EAMG manifestations appears 2 weeks after the booster injection. ${ }^{26}$ When compared with TAChR-induced EAMG, R97-116-induced EAMG shows a different time course, which is characterized by a slower progression over time and a slightly wider clinical inhomogeneity among immunized animals. ${ }^{26}$ Due to the considerably better feasibility of working with a peptide of the rat AChR instead of the whole AChR extracted from T. californica, several recently published studies on new therapeutic strategies have been performed in the R97-116 experimental model. ${ }^{32-35}$

\section{Passive transfer of EAMG}

EAMG can be also induced by passive transfer of auto-Abs via two distinct mechanisms: either with daily injections into healthy recipient animals of serum IgG fraction isolated from MG patients ${ }^{15}$ or with anti-AChR antibodies purified from AChR-immunized donor animals in chronic EAMG. ${ }^{1}$ Alternatively, passive EAMG can be induced via administration of monoclonal antibodies (IgG1 or IgG2a) which are directed to the AChR $\alpha$-subunit, either derived from AChR-immunized animals ${ }^{36}$ or cell line culture supernatants, ${ }^{37}$ which trigger EAMG symptoms in the recipient animals within 24 hours. This EAMG induction protocol has proved to be the perfect model not only for characterizing the immunopathogenesis of AChR-MG and for testing the pathogenicity of other antigentargeted auto-Abs but also for evaluating the therapeutic potentials of drugs specifically aimed to reduce auto-Ab pathogenic effects. ${ }^{38}$

\section{Adoptive transfer of EAMG}

EAMG can be induced via the transplantation of human tissues or cells in severe combined immunodeficiency (SCID) mice, lacking mature B- and T-cells and tolerating xenografts. ${ }^{39,40}$ Published studies show that SCID mice engrafted with thymus tissue fragments of $\mathrm{MG}$ patients produce human anti-mouse AChR antibodies 1-2 weeks after transplantation, demonstrating that a myasthenic thymus contains all the cellular components required for producing auto-Abs and maintaining their synthesis for at least 11 weeks after transplantation. ${ }^{39}$ Similarly, SCID mice injected with peripheral blood lymphocytes, derived from MG patients, show the typical signs of the human disease, which is characterized by circulating anti-AChR antibodies and human IgG deposits at the NMJ, and demonstrate that only $\mathrm{CD}^{+} \mathrm{T}$-cells, and not $\mathrm{CD}^{+} \mathrm{T}$-cells, are necessary for the pathogenesis of the disease. ${ }^{40}$ Finally, clinical manifestations of $\mathrm{MG}$ are also observed in AChR-immunized SCID mice and simultaneously injected with peripheral blood lymphocytes isolated from healthy controls. ${ }^{41}$

\section{Newly emerged auto-antigens in MG and new EAMG models}

The majority of patients with generalized MG (85\%) and with ocular MG (50\%) develop antibodies against AChR, usually belonging to IgG1 and IgG3 isotypes; these autoAbs can be detected by the standard radioimmunoassay method. ${ }^{1}$ In $\sim 40 \%$ of MG patients without anti-AChR antibodies (AChR-negative $\mathrm{MG}$ ), antibodies directed to a postsynaptic muscle-specific tyrosine kinase (MuSK) can be 
detected, ${ }^{42}$ predominantly of the IgG4 type. ${ }^{43,44}$ The clinical disease, which is characterized by bulbar and facial muscle weakness and extreme fatigue, can be difficult to treat in an effective manner. MuSK auto-Abs affect the NMJ dispersing AChR clusters. Indeed, MuSK together with neural agrin, low-density lipoprotein receptor-related protein 4 (LRP4), downstream of tyrosine kinase 7 , and rapsyn is crucial in stabilizing postsynaptic AChRs clusters. ${ }^{45}$ Experimental animals actively immunized with MuSK (active MuSK EAMG) develop MuSK auto-Abs and muscle weakness, which are accompanied by reduced postsynaptic AChR numbers, decremented amplitudes of endplate potentials, and failure of neuromuscular transmission. ${ }^{46-48}$ Although MuSK immunization stimulates the production of all antibody isotypes, noncomplement-fixing IgG1, the mouse analog of human IgG4, is the dominant anti-MuSK Ig isotype in both sera and NMJs. ${ }^{47}$ Moreover, MuSK-immunized mice sera and supernatants of cultured lymph node cells show high levels of interleukin (IL)-4 and IL-10, suggesting a role for Th2-type cells in the activation of anti-MuSK IgG1. ${ }^{49}$ Similar results have been found in mice injected with IgG from MG patients positive for MuSK auto-Ab (passive transfer of MuSK EAMG). ${ }^{9,45,51,52}$ Thanks to these models, besides enlightening the mechanisms by which MuSK antibodies disrupt synaptic function at the NMJ, clues for the pathogenesis of IgG4related diseases have been given, which might in turn be of great value for developing specific therapies. ${ }^{47,52,53}$

Moreover, recent studies in MG patients double negative for anti-AChR and anti-MuSK have identified auto-Abs against LRP4, an agrin receptor critical for NMJ formation. ${ }^{54-58}$ LRP4 auto-Abs have been demonstrated to be pathogenic; ${ }^{59,60}$ indeed, mice immunized with the extracellular domain of LRP4 produce anti-LRP4 antibodies and show MG-like symptoms. ${ }^{60}$ Moreover, mouse anti-LRP4 antibodies inhibit agrin-induced MuSK activation and AChR clustering, thus showing potential pathophysiological mechanisms. Indeed, passive transfer experiments confirmed the pathogenicity of LRP4 antibodies and demonstrated that LRP4, which contributes to NMJ maintenance, is an autoantigen in $\mathrm{MG} .{ }^{60}$

\section{EAMG models for the investigation of therapeutic approaches}

The main aim of experimental MG is to understand the pathological mechanisms of the disease and to investigate potential new therapies ${ }^{16}$ in order to flank or replace the actual immunosuppressive therapies. Indeed, current conventional therapies for MG are not effective in a proportion of patients, and immunosuppressive drugs induce numerous side effects; hence, new approaches are necessary to suppress antigenspecific immune cells and reduce the undesired effects usually observed following the inhibition of the whole immune system in MG patients.

The recently studied new interventions on the EAMG model may be subdivided into five major classes on the basis of their general mechanism of action: 1) treatments to induce peripheral tolerance, via tolerizing agents or immunomodulating cellular delivery; 2) treatments to induce immunomodulation via biological agents, such as cytokines or probiotics; 3 ) newly developed pharmacological approaches; 4) inhibitors of complement activity; and 5) molecular biology approaches such as RNA/microRNA interference. The following sections serve as a general excursus on those approaches, which are also schematically summarized in Table 3.

\section{Induction of peripheral tolerance}

The most supported pathogenetic hypothesis for MG induction is the loss of self-tolerance in the thymus, ${ }^{7,61}$ which induces the production of AChR-specific auto-reactive $\mathrm{CD}^{+}$ T-cell and consequently anti-AChR auto-Abs. The development of EAMG seems to be caused by a disruption of T-cell subset balance, which is characterized by an increase in Th1/ Th17 cells and a decrease in Th2/regulatory T-cells (Tregs). ${ }^{62}$ The immune response is normally kept under control by a

Table 3 Therapeutic approaches investigated via EAMG

\begin{tabular}{|c|c|}
\hline Approaches & References \\
\hline Induction of peripheral tolerance & $\begin{array}{l}\text { Ma et al, }{ }^{138} \text { Barchan et al, }{ }^{64} \\
\text { Im et al, }{ }^{65} \text { Maiti et al, }{ }^{66} \text { Okumura } \\
\text { et al },^{67} \text { Baggi et al }{ }^{68}\end{array}$ \\
\hline $\begin{array}{l}\text { Therapeutic potential of } \\
\text { immunomodulating dendritic } \\
\text { cells }\end{array}$ & $\begin{array}{l}\text { Yarilin et al, },^{73} \text { Duan et al, },^{74} \text { Sheng } \\
\text { et al, },^{78} \text { Li et al, }{ }^{81} \text { Sun et al }{ }^{84}\end{array}$ \\
\hline $\begin{array}{l}\text { Regulatory cells and suppressor } \\
\text { cells as therapeutic approach }\end{array}$ & Aricha et al, ${ }^{93}$ Nessi et al, ${ }^{94}$ Li et al ${ }^{98}$ \\
\hline $\begin{array}{l}\text { Other cell therapies for EAMG: } \\
\text { mesenchymal stem cells and } \\
\text { BIO cells }\end{array}$ & $\begin{array}{l}\text { Kong et al, }{ }^{99} \text { Kong et al, }{ }^{100} \\
\text { Sheng et al }{ }^{101}\end{array}$ \\
\hline Immunomodulation through & Im et al, ${ }^{102} \mathrm{Im}$ et al, ${ }^{108} \mathrm{Feferman}$ et al, ${ }^{105}$ \\
\hline biological agents & $\begin{array}{l}\text { Aricha et al, }{ }^{103} \text { Feferman et al, }{ }^{104} \text { Yao } \\
\text { et al, }{ }^{106} \text { Shi et al, },{ }^{107} \text { Chae et al }{ }^{110}\end{array}$ \\
\hline $\begin{array}{l}\text { Pharmacological } \\
\text { immunotherapy }\end{array}$ & $\begin{array}{l}\text { Ubiali et al, }{ }^{113} \text { Marolda et al, }{ }^{114} \text { Gomez } \\
\text { et al, }{ }^{112} \text { Xie et al }{ }^{32}\end{array}$ \\
\hline $\begin{array}{l}\text { Prevention of complement- } \\
\text { mediated NMJ destruction }\end{array}$ & $\begin{array}{l}\text { Sun et al, }{ }^{123} \text { Lin et al, }{ }^{121} \text { Kaminski } \\
\text { et al, }{ }^{120} \text { Morgan et al, }{ }^{117} \text { Soltys et al }{ }^{124}\end{array}$ \\
\hline $\begin{array}{l}\text { MicroRNA interference as } \\
\text { future gene therapy }\end{array}$ & Wang et al, ${ }^{130}$ Zhang et al $\left.\right|^{139}$ \\
\hline
\end{tabular}

Abbreviations: EAMG, experimental autoimmune myasthenia gravis; NMJ, neuromuscular junction. 
peripheral immune surveillance system, which deletes selfreactive T-cells escaped from thymic selection. This immune surveillance is maintained in a steady state by the balance between different $\mathrm{CD} 4^{+} \mathrm{T}$-cell subsets, breaking that balance leads to failure of immune surveillance. ${ }^{63}$ Therefore, the goal of some therapeutic strategies is the induction of peripheral tolerance and reestablishment of the balance between Th1/Th2/Th17/Treg cell responses.

Nasal administration to myasthenic rats of human recombinant fragments of the AChR $\alpha$-subunit, including the whole extracellular domain of AChR (Ho1-210), induces tolerance to the AChR. Such treatment prevents the development and suppresses the progression of EAMG, inhibiting antigenspecific T-cell proliferative responses and reducing the levels of anti-AChR antibodies. ${ }^{64,65}$ Similar tolerization effect is achieved in EAMG rats, which is orally treated during the acute and chronic phase with a human recombinant extracellular domain of AChR $\alpha$-subunit (Ho1-205), inducing a shift from Th1 to Th2 cell response and from IgG2 to IgG1 antibody isotypes.$^{65}$ Analogous evidence is observed after the oral administration of AChR epitopes. ${ }^{66-68}$ Indeed, the nasal administration of the To146-162 synthetic peptide, corresponding to the immunodominant epitope of TAChR $\alpha$-subunit, to mice immunized with TAChR reduces T-cell proliferative response to TAChR and Ta146-162 peptides, the production of pathogenic antibodies, and the loss of muscle AChR content, thus modulating ongoing disease ${ }^{68}$

\section{Therapeutic potential of immunomodulating dendritic cells}

Another therapeutic strategy, which is designed to suppress the antigen-specific response in MG, involves the cellular components that participate in the control of peripheral tolerance to the AChR. Dendritic cells (DCs) are specialized antigen-presenting cells that are able to initiate a primary immune response by activating naïve T-cells. ${ }^{69}$ DCs first recognize and process antigens in the periphery, then migrate to lymphoid organs where they expose the processed peptides to naïve T-cells. In vitro, not only the maturation and function of DCs can be regulated in different pathways: the upregulation of costimulatory molecules (CD83, CD40, CD80, CD86) and major histocompatibility complex class II on DCs is essential to activate T-cells,${ }^{69}$ but also immature DCs can tolerize T-cells. ${ }^{70,71}$ Depending on their maturation and differentiation state, DCs can acquire either a tolerogenic or an immunogenic activity. ${ }^{69}$ In the absence of inflammation, immature DCs control peripheral tolerance by promoting Treg differentiation; instead, inflammatory conditions provoke morphological and functional changes leading to mature DCs that are able to induce the activation of effector T-cells. ${ }^{10,72}$

Several published studies show that DC vaccine can induce tolerance and protect from autoimmune diseases. In this line, many therapeutic strategies aim to modulate in vitro DC maturation and differentiation with anti-inflammatory agents or growth factors. For instance, DC isolated from spleens of healthy rats and conditioned in vitro with transforming growth factor beta 1 (TGF- $\beta 1$ ) can be arrested at their immature differentiation stage, and their administration to AChR-immunized rats reduces the severity of EAMG symptoms. ${ }^{73}$ In addition, spleen-derived DCs exposed to IL-10 in vitro induce EAMG amelioration when injected intraperitoneally into AChR-immunized rats, due to the DC modulation of T- and B-cell responses. ${ }^{74}$ Moreover, healthy animals injected with bone marrow DCs pulsed in vitro with $\mathrm{AChR}$, and subsequently immunized with $\mathrm{AChR}$, do not show clinical signs of EAMG, thus confirming the role of immature DCs in the control of peripheral tolerance. ${ }^{75-77}$ Indeed, DCs engineered to present $\mathrm{AChR}$ epitopes can specifically target AChR-specific T-cells, resulting in the reduction in both AChR-T-cell responses and anti-AChR antibodies. Besides TGF- $\beta$ and IL-10, also the treatment with granulocyte-macrophage colony-stimulating factor can suppress the development of EAMG manifestations when administered to mice before $\mathrm{AChR}$ immunization, ${ }^{78}$ thanks to the activation of specific DC subpopulations and expansion of the Treg compartment. ${ }^{78}$

Similarly, also DCs incubated with atorvastatin, a statin therapeutically employed for reducing cardiovascular diseases which is known to show a strong immunomodulatory activity ${ }^{79,80}$ especially inhibiting the maturation and function of antigen-presenting cells, acquire an immature tolerizing phenotype. Indeed, spleen-derived DCs extracted from ongoing EAMG rats can be in vitro tolerized by statin treatment and can improve clinical symptoms when injected into recipient EAMG rats, inducing an increase in $\mathrm{CD} 4{ }^{+} \mathrm{CD} 25^{+}$Tregs and Foxp 3 expression, while decreasing lymphocyte proliferation and shifting cytokine profile from Th1/Th17- to Th2-type cytokines. ${ }^{81,82}$ Tolerized DC-induced Th cell shift is crucial for the amelioration of EAMG symptoms, indeed also bone-marrow-derived DCs, RelB silenced and pulsed with To146-162, are able to suppress EAMG progression in mice, by inducing a positive shift in favor of Th2/Treg responses ${ }^{83}$ Finally, the tolerizing function of DCs can be exploited even to induce specific killing of AChR-targeted effector T-cells, 
as in the "Guided Missile" strategy in which genetically engineered DCs simultaneously target and eliminate the individual's unique AChR-specific T-cell repertoire, by presenting AChR epitopes and expressing Fas ligand. ${ }^{84}$ Eventually, very recent data indicate that aside from the classical cell therapy, a tolerizing effect can be obtained in EAMG also via the delivery of exosomes produced by immature DCs. ${ }^{85}$

\section{Regulatory cells and suppressor cells as therapeutic approach}

Another therapeutic approach acts directly on the immune cells devoted to $\mathrm{T}$ - and B-cell responses, that is, $\mathrm{CD} 4{ }^{+} \mathrm{CD} 25^{+}$ Treg and myeloid-derived suppressor cells (MDSCs). Tregs arise in the thymus, which represent $5 \%-10 \%$ of $\mathrm{CD}^{+} \mathrm{T}$-cells in the periphery and constitutively express CD25 molecule (IL-2 receptor $\alpha$-chain). They play an essential role in the maintenance of peripheral tolerance, suppressing the proliferation and cytokine production of $\mathrm{CD}^{+}$effector T-cells. ${ }^{86-88}$ Myasthenic patients often show a defect in Treg subset: the number of Tregs is reduced in the peripheral blood, ${ }^{89,90}$ while their suppressive function, but not their number, is altered in the thymus. ${ }^{91,92}$ Thus, the restoration or expansion of the Treg compartment can represent an important therapeutic tool for the disease. Tregs can be in vitro induced from $\mathrm{CD}^{+}$ T-cells from spleens of healthy rats, which are stimulated with anti-CD3 and anti-CD28 antibodies in the presence of TGF- $\beta$ and IL-2. Such induced $C D 4{ }^{+} \mathrm{CD} 25^{+}$Tregs, sharing identical functional features with naturally occurring Tregs, can suppress clinical signs of EAMG in AChR-immunized rats. ${ }^{93}$ Similarly, also naturally occurring Tregs, purified from spleens of healthy rats, can modulate EAMG progression when administered to AChR-immunized rats, ${ }^{94}$ through the reduction in specific T-cell proliferation, decrease in pathogenic auto-Abs titer, and increase in muscle AChR content. ${ }^{94}$

Besides Tregs, also MDSCs derived from myeloid progenitors have a therapeutic effect in ongoing EAMG. These cells, originally identified in tumors, ${ }^{95}$ inhibit both innate and adaptive immunity, ${ }^{96,97}$ seemingly via antigen-specific immunosuppression in peripheral organs. Adoptive transfer of these MDSCs is able to reverse EAMG progression, specifically suppressing AChR-specific T-cell responses, decreasing serum anti-AChR IgGs, reducing complement activation at the NMJ, and also directly inhibiting B-cells through multiple mechanisms, including PGE2, inducible nitric oxide synthase, and arginase..$^{98}$

\section{Other cell therapies for EAMG: mesenchymal stem cells and BIO cells}

A further candidate cell therapy for human $\mathrm{MG}$ is represented by bone marrow stromal cells, which can modulate the functions of T- and B-cells, natural killer cells, and DCs. In particular, bone marrow stromal cells inhibit lymphocyte responses to different stimuli by the secretion of immunosuppressive factors. ${ }^{99}{ }^{100}$ Indeed, stromal cells, derived from healthy rats, induce a strong reduction in disease severity when injected into EAMG rats at clinical onset. Such treatment results in the secretion of immunosuppressive factors, such as indoleamine 2,3-dioxygenase and TGF- $\beta$, thus suppressing both T- and B-cell responses to the immunizing antigen and production of modulating cytokine and decreasing Th1 and Th17 subsets while increasing Th2 and Treg subpopulations. ${ }^{99,100}$

In addition, IL-10-competent B-cells, known as B10, characterized by the expression of CD5 and high CD1 $\left(\mathrm{CD} 1 \mathrm{dhiCD}^{+}\right)$can prevent or suppress EAMG, either indirectly through low-dose granulocyte-macrophage colonystimulating factor administration, which increases the number of circulating B10 cells, or directly by adoptive transfer of CD1dhiCD5 ${ }^{+} \mathrm{B}-c e l l s . ~ B 10$ cells alter T-cell cytokine profile, downregulate mature DC markers, and expand Treg compartment, while directly blocking B-cell proliferation and auto$\mathrm{Ab}$ production in an IL-10-dependent manner. ${ }^{101}$

\section{Immunomodulation through biological agents}

Besides tolerization induction and cell suppression, direct modulation of key immunological factors can be pivotal in the therapy of autoimmunity. Indeed, cytokines and costimulatory molecules are important in autoimmune pathogenesis, as shown in EAMG rats treated with antibodies either to proinflammatory, costimulatory factors or to chemokines, which suppress the disease but acting via different complementing mechanisms. For instance, the stimulatory molecule CD40L, studied by EAMG experiments in CD40L knock-out (KO) mice or via anti-CD40L antibodies injection, is fundamental for T- and B-cell engagement, activation, and EAMG induction. ${ }^{102}$ Similarly, EAMG experiments have proved the role of the pleiotropic inflammatory cytokine IL-6 in B/T-cell function and autoimmune reaction maintenance. Indeed, the administration of anti-IL-6 antibodies suppresses EAMG symptoms during both the acute and the chronic phase, thanks to an induced shift in favor of Tregs, instead of Th17 cells, accompanied by reduced numbers of B-cells. ${ }^{103}$ Similarly to IL-6 blockade, also the inhibition of interferon $\gamma$ inducible 
protein 10 (IP-10), a highly inducible chemoattractant for activated T-cells leads to immunomodulation and the attenuation of EAMG symptoms, when either anti-IP-10 antibodies or IP-10 receptor (CXCR3) antagonists are administered. ${ }^{104,105}$ Moreover, the cytokine IL-9 and IL-18 are crucial for EAMG development. Indeed, IL-9 neutralization via targeted antibody ameliorates the symptoms of EAMG, decreasing effector T-cells and altering humoral responses, ${ }^{106}$ and IL-18 KO mice are resistant to the disease. ${ }^{107}$ Similarly, anti-IL-18 antibodies suppress EAMG, increasing TGF- $\beta$ levels while decreasing AChR-reactive Th1-type cellular responses. ${ }^{108}$ An increased production of TGF- $\beta$ is also observed when IL-2/ anti-IL-2 mAb complexes are administered, which inhibit the development of EAMG, mediating the expansion of $\mathrm{CD} 4{ }^{+} \mathrm{CD} 25^{+} \mathrm{Foxp}^{+}$Treg cells and the conversion of peripheral and circulating $\mathrm{CD} 4^{+} \mathrm{CD} 25^{-} \mathrm{T}$-cells in Treg, leading to a shift of Th1/Th2 ratio in favor of a Th2 phenotype. ${ }^{109}$ Aside from monoclonal antibody blockade, other strategies have been tested to efficiently inhibit proinflammatory cytokines in EAMG, such as the use of a specific caspase-1 inhibitor, which blocks caspase-1-mediated cleavage of both IL-1 $\beta$ and IL-18 precursors into their functional forms, thus ameliorating EAMG symptoms. ${ }^{33}$

Finally, also less potent immunomodulatory agents, such as live probiotic bacteria administered orally, may have a beneficial role on EAMG symptoms, when given following a prophylactic schedule, through the generation of regulatory DCs that express increased levels of IL-10 and TGF- $\beta$ and are able to convert $\mathrm{CD}^{+}{ }^{+}$T-cells into $\mathrm{CD}^{+}{ }^{+}$Foxp $3{ }^{+}$Treg. ${ }^{110}$

\section{Pharmacological immunotherapy}

Besides approved current pharmacological therapies for the treatment of $\mathrm{MG},{ }^{111}$ other emerging drugs, such as bortezomib and pixantrone (BBR2778) (PIX), show excellent efficacy in suppressing EAMG. ${ }^{12-114}$ Bortezomib, an inhibitor of proteasomes, which depletes both short- and long-lived plasma cells, was shown to induce apoptosis in bone marrow cells and reduce the amount of plasma cells in EAMG rats, resulting in reduced anti-AChR auto-Ab titers, improved neuromuscular transmission, and decreased clinical symptoms. ${ }^{12}$ Differently from bortezomib, PIX is an antineoplastic drug, which is structurally related to mitoxantrone. Both drugs are DNA intercalants and topoisomerase II inhibitors, but PIX is characterized by a reduced cardiotoxicity compared with mitoxantrone. When administrated to AChRimmunized rats via different treatment schedules, either preventive (before clinical onset) or therapeutic protocol (at overt clinical symptoms), PIX is able to suppress antigenspecific T-cell proliferative responses in a dose-dependent manner, reducing the levels of pathogenic antibodies and increasing muscle AChR content. ${ }^{113}$ Interestingly, even if clinical symptoms could be improved only by repeated PIX administrations, allowing stable serum drug levels, a single administration is already able to suppress AChR-specific immune responses in primed rats, inhibiting only proliferating T-cells without impairing DC differentiation and B-cell viability. ${ }^{114}$ Another pharmacological treatment recently tested in EAMG is the all-trans retinoic acid (ATRA), a vitamin A metabolite with diverse immunomodulatory actions, which is used therapeutically in the treatment of some autoimmune diseases. The study in the EAMG model allowed deeper inside in its mechanism of action, which is still unknown. Intraperitoneal injection of ATRA in EAMG rats ameliorated clinical symptoms, reduced total anti-AChR auto-Abs titers, and changed follicular T-cells levels, thus restoring the Th1/Th2/Th17/Treg balance. ATRA altered the Th cell distribution in EAMG animals resulting in a reduction in Th1/Th17/follicular T helper cells (Tfh) cells and an increase in Th2/Treg/regulatory follicular T cells (Tfr) cell types. ${ }^{33}$ These results highlight the importance of EAMG in testing pharmacological drugs to assess their efficacy and to decipher their mechanism of action, offering new possibilities for the treatment of human MG.

\section{Prevention of complement-mediated NMJ destruction}

The role of complement at the level of the NMJ has been extensively studied in EAMG models. Indeed, complement activation plays an essential role in the destruction of the postsynaptic membrane (reviewed in the study by Tuzun and Christadoss ${ }^{15}$ ). Although C3a and C5a promote inflammation by recruiting and activating phagocytic cells, $\mathrm{C} 3 \mathrm{~b}$ and C4b simultaneously lead to muscle membrane lysis. ${ }^{116,117}$ Depleting the complement cascade via treatment with cobra venom factor decreases the formation of anti-AChR antibodies/AChR complexes and ameliorates the acute phase of EAMG in rats. ${ }^{118}$ More specifically, the effects of several complement components have been analyzed in various transgenic models. For instance, C5-deficient mice show a mild EAMG incidence and little decrease in muscle. ${ }^{119}$ Besides, treatment with soluble recombinant form of human complement receptor 1 (sCR1) reduces EAMG severity. ${ }^{38}$ The role of the MAC has also been studied in acute, passively transferred EAMG in Wistar rats, where 
administered anti-C6 Fab leads to the inhibition of MAC formation and suppression of EAMG clinical and electrophysiological signs. ${ }^{32}$ Regulatory proteins that inhibit MAC formation (such as MIRL-CD59 that inhibits MAC assembly) and control the activation of the complement cascade (such as the decay-accelerating factor or CD55, which inactivates $\mathrm{C} 3$ and $\mathrm{C} 5$ convertase enzymes) represent crucial players in EAMG development, and their modulation has been a target of recent experimental approaches aimed at complement depletion. ${ }^{117,120-123}$ Pharmacological inhibition of the complement activation pathway is an alternative strategy to depleting approaches. Indeed, the administration of rEV576, a specific C5 complement component inhibitor, is able to reduce the severity of passive transfer of EAMG and the progression of acute experimental MG, reducing C9 deposits at the NMJ. ${ }^{124}$ Another strategy is that of increasing the resistance of the NMJ to complement-mediated lysis. An increased interaction between rapsyn and AChR may stabilize the receptor molecules, conferring greater NMJ resistance, leading to minor AChR loss and muscle weakness in acute EAMG. ${ }^{125}$ Thus, the overexpression of rapsyn may represent a further therapeutic option, but unfortunately the increased expression of rapsyn alone is not able to efficiently anchor the AChR to the postsynaptic membrane in chronic EAMG, once the destruction of the NMJ has already occurred. ${ }^{126}$

\section{MicroRNA interference as future gene therapy}

MicroRNAs have been shown to act as regulators of gene expression and play an important role in immune homeostasis and autoimmunity susceptibility. ${ }^{127}$ Indeed, it has been recently shown that miR-146a is upregulated in activated B-cells in response to rat AChR 97-116 peptide, and this upregulation can be attenuated by miR-146a-specific antagonist. ${ }^{128}$ Consequently, miR-146a systemic silencing ameliorates EAMG symptoms in mice via B-cell blocking, including decreased production of anti-R97-116 antibodies, class switching, reduced numbers of plasma cells and memory B-cells and B-1 cells. ${ }^{128}$ Similar data were published regarding another miRNA, miR-155, that is upregulated in AChR-stimulated B-cells. ${ }^{129}$ The systemic delivery of a miR155 inhibitor conjugated to anti-CD20 single-chain antibody impairs B-cell signaling and reduces EAMG autoimmune reaction in mice. ${ }^{129}$ Conversely, it was recently demonstrated that another miRNA, miR-145, is downregulated in peripheral monocytes from EAMG rats, especially in $\mathrm{CD}^{+} \mathrm{T}$-cells, and its in vitro upregulation in a DC-T-cell coculture setup suppresses Th 17 cell response. ${ }^{130}$ Finally, the administration of lentiviral miR-145 during ongoing EAMG decreased the severity of symptoms and production of IL-17. ${ }^{130}$ Altogether, these results provide insights into the role of miRNA in EAMG pathogenesis and open a new prospective for EAMG/ MG gene therapy.

\section{Limitations of the animal model}

As discussed so far, the EAMG model has been extensively used to analyze various aspects of MG pathology and experimental therapies. Nevertheless, there are limitations in using this animal model. For instance, EAMG can be easily affected by the induction procedure, despite the publication of several detailed guidelines which should help obtaining high standard disease models. ${ }^{38,131,132}$ Indeed, the chosen experimental parameters and procedures affect the disease time course, incidence, and severity. For example, strong EAMG clinics in susceptible strains, or using potent adjuvants, mean unbearable animal suffering and increased number of animal deaths, which in turn damage the statistical power of the results. On the other side, mild EAMG scores are scarcely effective in demonstrating beneficial treatment effects. ${ }^{131}$

Moreover, despite faithfully reproducing many aspects of the human pathology, the experimental model still presents several discrepancies with the human disease (Table 1), such as the absence of a spontaneous disease in experimental animals, accounting for a strongly different genetic background. Besides, the role of the thymus as the main site for initiating, sustaining, and maintaining the disease $^{7,61,133}$ has so far not been paralleled in the animal models, despite only few old reports ${ }^{6,134,135}$ and very recent data indicating a pathogenic role of thymic epithelial cells and DCs in the myasthenic rat, in contributing to developing an active inflammatory milieu. ${ }^{10}$

Eventually, the most relevant limitation of the animal model is being an animal model. Mice and rats are bred in controlled facilities and experiments are always performed on syngeneic animals. There is very little or no involvement of genetic drift or even environmental exposure. In the human disease, instead, environmental factors, such as viral or microbial agents, play a pivotal role in the pathogenesis of autoimmunity. ${ }^{61,133}$

Finally, in an ever more sensible and ethically correct research environment, we must bear in mind that, when possible, alternative strategies must always be pursued. EAMG has been fundamental in discovering the pathogenic mechanisms of MG and in developing several therapeutic strategies, 
at the expense of suffering animals. Researchers must now make an effort to set up and create alternative methodologies such as complex cellular cultures for validating pathogenic hypothesis ${ }^{10}$ and new treatments. ${ }^{136}$

\section{Conclusion}

MG is a rare chronic autoimmune disease involving different compartments of the organism: the immune system and the NMJ. In vitro models, which are able to fully represent complex pathologies where more tissues and systems are involved, are not yet available but more effort should be given in order to obtain complex in vitro setups mimicking the autoimmune inflammatory milieu. The EAMG model allows the investigation of both the muscle compartment and the immune system, focusing on the pathogenic mechanisms and the clinical outcome. Thus, EAMG is an essential tool for understanding pathogenic mechanisms and investigating new therapies, which may later be translated to clinical trials.

Unfortunately, several treatment strategies effective in EAMG failed when transferred to the human disease. Indeed, EAMG has a less complex pathogenesis compared with the human disease, as it is performed on syngeneic animals that bred in controlled conditions, especially in terms of genetic predisposition and environmental factors such as the exposure to viral antigens. Nevertheless, EAMG has been of great value first in understanding the pathogenic mechanisms of auto-Abs and in proving the efficacy of both pharmacological treatments and cell therapy strategies with results that encourage the investigation of the human disease. A similar approach is necessary for any new immunosuppressive or immunomodulating compound of potential interest. Always considering Russell and Burch's 3R rule for the replacement of experimental animal procedures with alternative methods, the reduction in the number of used animals, and refinement of the animal conditions, ${ }^{137}$ we cannot forget that complex diseases, of which MG is a prototypical representative, need to be addressed with preclinical research in order to obtain more efficient therapies. Despite the evident differences between EAMG and $\mathrm{MG}$, most importantly the axiom that the former cannot spontaneously arise in laboratory animals, the experimental approach remains an unavoidable and irreplaceable method to discover new efficient therapies.

\section{Acknowledgments}

We regret that due to space constraints, we could not include the essential work of many investigators and colleagues.
We acknowledge the Italian Ministry of Health Grant PE-2011-02346818 for financial support.

\section{Disclosure}

The authors report no conflicts of interest in this work.

\section{References}

1. Lindstrom JM, Seybold ME, Lennon VA, et al. Antibody to acetylcholine receptor in myasthenia gravis. Prevalence, clinical correlates, and diagnostic value. Neurology. 1976;26:1054-1059.

2. Trotter JL, Ringel SP, Cook JD, et al. Morphologic and immunologic studies in experimental autoimmune myasthenia gravis and myasthenia gravis. Neurology. 1977;27:1120-1124.

3. Meriggioli MN. Myasthenia gravis with anti-acetylcholine receptor antibodies. Front Neurol Neurosci. 2009;26:94-108.

4. Tzartos SJ, Morel E, Efthimiadis A, et al. Fine antigenic specificities of antibodies in sera from patients with D-penicillamine-induced myasthenia gravis. Clin Exp Immunol. 1988;74:80-86.

5. Newsom-Davis J, Willcox N, Calder L. Thymus cells in myasthenia gravis selectively enhance production of anti-acetylcholine-receptor antibody by autologous blood lymphocytes. $N$ Engl J Med. 1981;305: 1313-1318.

6. Melms A, Luther C, Stoeckle C, et al. Thymus and myasthenia gravis: antigen processing in the human thymus and the consequences for the generation of autoreactive T cells. Acta Neurol Scand Suppl. 2006;183: 12-13.

7. Cavalcante P, Le Panse R, Berrih-Aknin S, et al. The thymus in myasthenia gravis: site of "innate autoimmunity"? Muscle Nerve. 2011;44:467-484

8. Hoedemaekers AC, van Breda Vriesman PJ, De Baets MH. Myasthenia gravis as a prototype autoimmune receptor disease. Immunol Res. 1997; 16:341-354.

9. Vincent A, Leite MI, Farrugia ME, et al. Myasthenia gravis seronegative for acetylcholine receptor antibodies. Ann N Y Acad Sci. 2008;1132:84-92.

10. Cordiglieri C, Marolda R, Franzi S, et al. Innate immunity in myasthenia gravis thymus: pathogenic effects of Toll-like receptor 4 signaling on autoimmunity. J Autoimmun. 2014;52:74-89.

11. Drachman DB. Autonomic "myasthenia": the case for an autoimmune pathogenesis. J Clin Invest. 2003;111:797-799.

12. Vincent A. Unravelling the pathogenesis of myasthenia gravis. Nat Rev Immunol. 2002;2:797-804.

13. Vincent A, Drachman DB. Myasthenia gravis. Adv Neurol. 2002;88: $159-188$.

14. Engel AG, Lambert EH, Howard FM. Immune complexes (IgG and C3) at the motor end-plate in myasthenia gravis: ultrastructural and light microscopic localization and electrophysiologic correlations. Mayo Clin Proc. 1977;52:267-280.

15. Toyka KV, Brachman DB, Pestronk A, et al. Myasthenia gravis: passive transfer from man to mouse. Science. 1975;190:397-399.

16. Fuchs S, Aricha R, Reuveni D, et al. Experimental autoimmune myasthenia gravis (EAMG): from immunochemical characterization to therapeutic approaches. J Autoimmun. 2014;54:51-59.

17. Patrick J, Lindstrom J, Culp B, et al. Studies on purified eel acetylcholine receptor and anti-acetylcholine receptor antibody. Proc Natl Acad Sci U S A. 1973;70:3334-3338.

18. Dau PC. Plasmapheresis in idiopathic inflammatory myopathy Experience with 35 patients. Arch Neurol. 1981;38:544-552.

19. Antozzi C, Gemma M, Regi B, et al. A short plasma exchange protocol is effective in severe myasthenia gravis. J Neurol. 1991;238:103-107.

20. Conti-Fine BM, Milani M, Kaminski HJ. Myasthenia gravis: past, present, and future. J Clin Invest. 2006;116:2843-2854.

21. Engel AG, Fumagalli G. Mechanisms of acetylcholine receptor loss from the neuromuscular junction. Ciba Found Symp. 1982;90:197-224. 
22. Gomez CM, Richman DP. Anti-acetylcholine receptor antibodies directed against the alpha-bungarotoxin binding site induce a unique form of experimental myasthenia. Proc Natl Acad Sci U S A. 1983;80: 4089-4093.

23. Baggi F, Antozzi C, Toscani C, et al. Acetylcholine receptor-induced experimental myasthenia gravis: what have we learned from animal models after three decades? Arch Immunol Ther Exp (Warsz). 2012;60: 19-30.

24. Christadoss P, Poussin M, Deng C. Animal models of myasthenia gravis. Clin Immunol. 2000;94:75-87.

25. Link H, Xiao BG. Rat models as tool to develop new immunotherapies. Immunol Rev. 2001;184:117-128.

26. Baggi F, Annoni A, Ubiali F, et al. Breakdown of tolerance to a selfpeptide of acetylcholine receptor alpha-subunit induces experimental myasthenia gravis in rats. J Immunol. 2004;172:2697-2703.

27. Baggi F, Annoni A, Ubiali F, et al. Immunization with rat-, but not Torpedo-derived 97-116 peptide of the AChR alpha-subunit induces experimental myasthenia gravis in Lewis rat. Ann NY Acad Sci. 2003;998:391-394.

28. Berman PW, Patrick J. Experimental myasthenia gravis. A murine system. J Exp Med. 1980;151:204-223.

29. Berman PW, Patrick J. Linkage between the frequency of muscular weakness and loci that regulate immune responsiveness in murine experimental myasthenia gravis. J Exp Med. 1980;152:507-520.

30. Lindstrom J. Experimental autoimmune myasthenia gravis. J Neurol Neurosurg Psychiatry. 1980;43:568-576.

31. Biesecker G, Gomez CM. Inhibition of acute passive transfer experimental autoimmune myasthenia gravis with Fab antibody to complement C6. J Immunol. 1989;142:2654-2659.

32. Xie X, Mu L, Yao X, et al. ATRA alters humoral responses associated with amelioration of EAMG symptoms by balancing Tfh/Tfr helper cell profiles. Clin Immunol. 2013;148:162-176.

33. Wang $\mathrm{CC}$, Li H, Zhang $\mathrm{M}$, et al. Caspase-1 inhibitor ameliorates experimental autoimmune myasthenia gravis by innate dendric cell IL-1-IL-17 pathway. J Neuroinflammation. 2015;12:118.

34. Li N, Mu L, Wang J, et al. Activation of the adenosine A2A receptor attenuates experimental autoimmune myasthenia gravis severity. Eur J Immunol. 2012;42:1140-1151.

35. Li N, Wang G, Yao X, et al. Adenosine receptor expression in a rat model of experimental autoimmune myasthenia gravis. Cell Immunol. 2014;290:217-225.

36. Tzartos S, Hochschwender S, Vasquez P, et al. Passive transfer of experimental autoimmune myasthenia gravis by monoclonal antibodies to the main immunogenic region of the acetylcholine receptor. J Neuroimmunol. 1987;15:185-194.

37. Piddlesden SJ, Jiang S, Levin JL, et al. Soluble complement receptor 1 (sCR1) protects against experimental autoimmune myasthenia gravis. J Neuroimmunol. 1996;71:173-177.

38. Kusner LL, Losen M, Vincent A, et al. Guidelines for pre-clinical assessment of the acetylcholine receptor-specific passive transfer myasthenia gravis model-Recommendations for methods and experimental designs. Exp Neurol. 2015;270:3-10.

39. Schonbeck S, Padberg F, Hohlfeld R, et al. Transplantation of thymic autoimmune microenvironment to severe combined immunodeficiency mice. A new model of myasthenia gravis. J Clin Invest. 1992;90: 245-250.

40. Wang ZY, Karachunski PI, Howard JF Jr, et al. Myasthenia in SCID mice grafted with myasthenic patient lymphocytes: role of CD4+ and CD8+ cells. Neurology. 1999;52:484-497.

41. Martino G, DuPont BL, Wollmann RL, et al. The human-severe combined immunodeficiency myasthenic mouse model: a new approach for the study of myasthenia gravis. Ann Neurol. 1993;34:48-56.

42. Hoch W, McConville J, Helms S, et al. Auto-antibodies to the receptor tyrosine kinase MuSK in patients with myasthenia gravis without acetylcholine receptor antibodies. Nat Med. 2001;7:365-368.

43. McConville J, Vincent A. Diseases of the neuromuscular junction. Curr Opin Pharmacol. 2002;2:296-301.
44. Ohta R, Motomura M. Autoantibodies detected in acetylcholine receptor antibody-negative myasthenia gravis. Rinsho Byori. 2014;62: $255-260$.

45. Ghazanfari N, Fernandez KJ, Murata Y, et al. Muscle specific kinase: organiser of synaptic membrane domains. Int J Biochem Cell Biol. 2011;43:295-298.

46. Jha $\mathrm{S}, \mathrm{Xu} \mathrm{K}$, Maruta $\mathrm{T}$, et al. Myasthenia gravis induced in mice by immunization with the recombinant extracellular domain of rat musclespecific kinase (MuSK). J Neuroimmunol. 2006;175:107-117.

47. Phillips WD, Christadoss P, Losen M, et al. Guidelines for pre-clinical animal and cellular models of MuSK-myasthenia gravis. Exp Neurol. 2015;270:29-40.

48. Ban J, Phillips WD. Mouse models of myasthenia gravis. Curr Pharm Des. 2015;21:2468-2486.

49. Ulusoy C, Kim E, Tuzun E, et al. Preferential production of IgG1, IL-4 and IL-10 in MuSK-immunized mice. Clin Immunol. 2014;151: 155-163.

50. Cole RN, Reddel SW, Gervasio OL, et al. Anti-MuSK patient antibodies disrupt the mouse neuromuscular junction. Ann Neurol. 2008;63:782-789.

51. Cole RN, Ghazanfari N, Ngo ST, et al. Patient autoantibodies deplete postsynaptic muscle-specific kinase leading to disassembly of the ACh receptor scaffold and myasthenia gravis in mice. J Physiol. 2010;588:3217-3229.

52. Morsch M, Reddel SW, Ghazanfari N, et al. Pyridostigmine but not 3,4-diaminopyridine exacerbates $\mathrm{ACh}$ receptor loss and myasthenia induced in mice by muscle-specific kinase autoantibody. $J$ Physiol. 2013;591:2747-2762.

53. Morsch M, Reddel SW, Ghazanfari N, et al. Muscle specific kinase autoantibodies cause synaptic failure through progressive wastage of postsynaptic acetylcholine receptors. Exp Neurol. 2012;237:286-295.

54. Pevzner A, Schoser B, Peters K, et al. Anti-LRP4 autoantibodies in AChR- and MuSK-antibody-negative myasthenia gravis. J Neurol. 2012;259:427-435.

55. Zhang B, Tzartos JS, Belimezi M, et al. Autoantibodies to lipoproteinrelated protein 4 in patients with double-seronegative myasthenia gravis. Arch Neurol. 2012;69:445-451.

56. Zong Y, Zhang B, Gu S, et al. Structural basis of agrin-LRP4-MuSK signaling. Genes Dev. 2012;26:247-258.

57. Higuchi O, Hamuro J, Motomura M, et al. Autoantibodies to low-density lipoprotein receptor-related protein 4 in myasthenia gravis. Ann Neurol. 2011;69:418-422

58. Motomura M, Higuchi O. Progress of myasthenia gravis: discovery of Lrp4 antibodies. Rinsho Shinkeigaku. 2012;52:1303-1305.

59. Barik A, Lu Y, Sathyamurthy A, et al. LRP4 is critical for neuromuscular junction maintenance. J Neurosci. 2014;34:13892-13905.

60. Shen C, Lu Y, Zhang B, et al. Antibodies against low-density lipoprotein receptor-related protein 4 induce myasthenia gravis. J Clin Invest. 2013;123:5190-5202.

61. Cavalcante P, Cufi P, Mantegazza R, et al. Etiology of myasthenia gravis: innate immunity signature in pathological thymus. Autoimmun Rev. 2013;12:863-874

62. Mu L, Sun B, Kong Q, et al. Disequilibrium of T helper type 1, 2 and 17 cells and regulatory $T$ cells during the development of experimental autoimmune myasthenia gravis. Immunology. 2009;128:e826-e836.

63. Schaffert H, Pelz A, Saxena A, et al. IL-17-producing CD4(+) T cells contribute to the loss of B-cell tolerance in experimental autoimmune myasthenia gravis. Eur J Immunol. 2015;45:1339-1347.

64. Barchan D, Souroujon MC, Im SH, et al. Antigen-specific modulation of experimental myasthenia gravis: nasal tolerization with recombinant fragments of the human acetylcholine receptor alpha-subunit. Proc Natl Acad Sci U S A. 1999;96:8086-8091.

65. Im SH, Barchan D, Fuchs S, et al. Suppression of ongoing experimental myasthenia by oral treatment with an acetylcholine receptor recombinant fragment. J Clin Invest. 1999;104:1723-1730.

66. Maiti PK, Feferman T, Im SH, et al. Immunosuppression of rat myasthenia gravis by oral administration of a syngeneic acetylcholine receptor fragment. J Neuroimmunol. 2004;152:112-120. 
67. Okumura S, McIntosh K, Drachman DB. Oral administration of acetylcholine receptor: effects on experimental myasthenia gravis. Ann Neurol. 1994;36:704-713.

68. Baggi F, Andreetta F, Caspani E, et al. Oral administration of an immunodominant T-cell epitope downregulates Th1/Th2 cytokines and prevents experimental myasthenia gravis. J Clin Invest. 1999;104: 1287-1295.

69. Banchereau J, Steinman RM. Dendritic cells and the control of immunity. Nature. 1998;392:245-252.

70. Jonuleit H, Schmitt E, Steinbrink K, et al. Dendritic cells as a tool to induce anergic and regulatory T cells. Trends Immunol. 2001;22: 394-400.

71. Krueger T, Wohlrab U, Klucken M, et al. Autoantigen-specific protection of non-obese diabetic mice from cyclophosphamide-accelerated diabetes by vaccination with dendritic cells. Diabetologia. 2003;46: 1357-1365.

72. Roncarolo MG, Levings MK, Traversari C. Differentiation of T regulatory cells by immature dendritic cells. J Exp Med. 2001;193:F5-F9.

73. Yarilin D, Duan R, Huang YM, et al. Dendritic cells exposed in vitro to TGF-beta1 ameliorate experimental autoimmune myasthenia gravis. Clin Exp Immunol. 2002;127:214-219.

74. Duan RS, Adikari SB, Huang YM, et al. Protective potential of experimental autoimmune myasthenia gravis in Lewis rats by IL-10-modified dendritic cells. Neurobiol Dis. 2004;16:461-467.

75. Xiao BG, Duan RS, Link H, et al. Induction of peripheral tolerance to experimental autoimmune myasthenia gravis by acetylcholine receptorpulsed dendritic cells. Cell Immunol. 2003;223:63-69.

76. Xiao BG, Huang YM, Link H. Dendritic cell vaccine design: strategies for eliciting peripheral tolerance as therapy of autoimmune diseases. BioDrugs. 2003;17:103-111.

77. Li L, Sun S, Cao X, et al. Experimental study on induction of tolerance to experimental autoimmune myasthenia gravis by immature dendritic cells. J Huazhong Univ Sci Technolog Med Sci. 2005;25:215-218.

78. Sheng JR, Li L, Ganesh BB, et al. Suppression of experimental autoimmune myasthenia gravis by granulocyte-macrophage colony-stimulating factor is associated with an expansion of FoxP3+ regulatory T cells. J Immunol. 2006;177:5296-5306.

79. Adamson P, Greenwood J. How do statins control neuroinflammation? Inflamm Res. 2003;52:399-403.

80. Greenwood J, Walters CE, Pryce G, et al. Lovastatin inhibits brain endothelial cell Rho-mediated lymphocyte migration and attenuates experimental autoimmune encephalomyelitis. FASEB J. 2003;17:905-907.

81. Li XL, Liu Y, Cao LL, et al. Atorvastatin-modified dendritic cells in vitro ameliorate experimental autoimmune myasthenia gravis by upregulated Treg cells and shifted Th1/Th17 to Th2 cytokines. Mol Cell Neurosci. 2013;56:85-95.

82. Li H, Wang CC, Zhang M, et al. Statin-modified dendritic cells regulate humoral immunity in experimental autoimmune myasthenia gravis. $\mathrm{Mol}$ Cell Neurosci. 2015;68:284-292.

83. Zhang Y, Yang H, Xiao B, et al. Effect of RelB-silenced BMDC pulsed with Talpha146 162 on immunoreaction of T cells primed with TAChR. Zhong Nan Da Xue Xue Bao Yi Xue Ban. 2010;35:38-44.

84. Sun W, Adams RN, Miagkov A, et al. Specific immunotherapy of experimental myasthenia gravis in vitro and in vivo: the Guided Missile strategy. J Neuroimmunol. 2012;251:25-32.

85. Bu N, Wu HQ, Zhang GL, et al. Immature dendritic cell exosomes suppress experimental autoimmune myasthenia gravis. J Neuroimmunol. 2015;285:71-75.

86. Fehervari Z, Sakaguchi S. Control of Foxp3+ CD25+CD4+ regulatory cell activation and function by dendritic cells. Int Immunol. 2004; 16:1769-1780

87. Piccirillo CA, d'Hennezel E, Sgouroudis E, et al. CD4+Foxp3+ regulatory $\mathrm{T}$ cells in the control of autoimmunity: in vivo veritas. Curr Opin Immunol. 2008;20:655-662.

88. Sakaguchi S. Naturally arising CD4+ regulatory t cells for immunologic self-tolerance and negative control of immune responses. Annu Rev Immunol. 2004;22:531-562.
89. Battaglia A, Di Schino C, Fattorossi A, et al. Circulating CD4+CD25+T regulatory and natural killer $\mathrm{T}$ cells in patients with myasthenia gravis: a flow cytometry study. J Biol Regul Homeost Agents. 2005;19:54-62.

90. Fattorossi A, Battaglia A, Buzzonetti A, et al. Circulating and thymic CD4 CD25 T regulatory cells in myasthenia gravis: effect of immunosuppressive treatment. Immunology. 2005;116:134-141.

91. Matsui N, Nakane S, Saito F, et al. Undiminished regulatory T cells in the thymus of patients with myasthenia gravis. Neurology. 2010;74: 816-820.

92. Balandina A, Lecart S, Dartevelle P, et al. Functional defect of regulatory CD4 (+) CD25+T cells in the thymus of patients with autoimmune myasthenia gravis. Blood. 2005;105:735-741.

93. Aricha R, Feferman T, Fuchs S, et al. Ex vivo generated regulatory $\mathrm{T}$ cells modulate experimental autoimmune myasthenia gravis. J Immunol. 2008;180:2132-2139.

94. Nessi V, Nava S, Ruocco C, et al. Naturally occurring CD4+CD25+ regulatory $\mathrm{T}$ cells prevent but do not improve experimental myasthenia gravis. J Immunol. 2010;185:5656-5667.

95. Young MR, Aquino S, Young ME. Differential induction of hematopoiesis and immune suppressor cells in the bone marrow versus in the spleen by Lewis lung carcinoma variants. J Leukoc Biol. 1989;45:262-273.

96. Hanson EM, Clements VK, Sinha P, et al. Myeloid-derived suppressor cells down-regulate L-selectin expression on CD4+ and CD8+ T cells. J Immunol. 2009;183:937-944.

97. Ostrand-Rosenberg S, Sinha P. Myeloid-derived suppressor cells: linking inflammation and cancer. J Immunol. 2009;182:4499-4506.

98. Li Y, Tu Z, Qian S, et al. Myeloid-derived suppressor cells as a potential therapy for experimental autoimmune myasthenia gravis. J Immunol. 2014;193:2127-2134.

99. Kong QF, Sun B, Bai SS, et al. Administration of bone marrow stromal cells ameliorates experimental autoimmune myasthenia gravis by altering the balance of Th1/Th2/Th17/Treg cell subsets through the secretion of TGF-beta. J Neuroimmunol. 2009;207:83-91.

100. Kong QF, Sun B, Wang GY, et al. BM stromal cells ameliorate experimental autoimmune myasthenia gravis by altering the balance of Th cells through the secretion of IDO. Eur J Immunol. 2009;39: 800-809.

101. Sheng JR, Quan S, Soliven B. CD1d(hi)CD5+ B cells expanded by GM-CSF in vivo suppress experimental autoimmune myasthenia gravis. J Immunol. 2014;193:2669-2677.

102. Im SH, Barchan D, Maiti PK, et al. Blockade of CD40 ligand suppresses chronic experimental myasthenia gravis by down-regulation of Th1 differentiation and up-regulation of CTLA-4. J Immunol. 2001;166:6893-6898.

103. Aricha R, Mizrachi K, Fuchs S, et al. Blocking of IL-6 suppresses experimental autoimmune myasthenia gravis. J Autoimmun. 2011;36: 135-141

104. Feferman T, Aricha R, Mizrachi K, et al. Suppression of experimental autoimmune myasthenia gravis by inhibiting the signaling between IFN-gamma inducible protein 10 (IP-10) and its receptor CXCR3. J Neuroimmunol. 2009;209:87-95.

105. Feferman T, Maiti PK, Berrih-Aknin S, et al. Overexpression of IFNinduced protein 10 and its receptor CXCR3 in myasthenia gravis. J Immunol. 2005;174:5324-5331.

106. Yao X, Kong Q, Xie X, et al. Neutralization of interleukin-9 ameliorates symptoms of experimental autoimmune myasthenia gravis in rats by decreasing effector T cells and altering humoral responses. Immunology. 2014;143:396-405.

107. Shi FD, Takeda K, Akira S, et al. IL-18 directs autoreactive T cells and promotes autodestruction in the central nervous system via induction of IFN-gamma by NK cells. J Immunol. 2000;165:3099-3104.

108. Im SH, Barchan D, Maiti PK, et al. Suppression of experimental myasthenia gravis, a B cell-mediated autoimmune disease, by blockade of IL-18. FASEB J. 2001;15:2140-2148.

109. Liu R, Zhou Q, La Cava A, et al. Expansion of regulatory $\mathrm{T}$ cells via IL-2/anti-IL-2 mAb complexes suppresses experimental myasthenia. Eur J Immunol. 2010;40:1577-1589. 
110. Chae CS, Kwon HK, Hwang JS, et al. Prophylactic effect of probiotics on the development of experimental autoimmune myasthenia gravis. PLoS One. 2012;7:e52119.

111. Mantegazza R, Bonanno S, Camera G, et al. Current and emerging therapies for the treatment of myasthenia gravis. Neuropsychiatr Dis Treat. 2011;7:151-160.

112. GomezAM, Vrolix K, Martinez-Martinez P, et al. Proteasome inhibition with bortezomib depletes plasma cells and autoantibodies in experimental autoimmune myasthenia gravis. J Immunol. 2011;186:2503-2513.

113. Ubiali F, Nava S, Nessi V, et al. Pixantrone (BBR2778) reduces the severity of experimental autoimmune myasthenia gravis in Lewis rats. J Immunol. 2008;180:2696-2703.

114. Marolda R, Ruocco C, Cordiglieri C, et al. Differential targeting of immune-cells by pixantrone in experimental myasthenia gravis. J Neuroimmunol. 2013;258:41-50.

115. Tuzun E, Christadoss P. Complement associated pathogenic mechanisms in myasthenia gravis. Autoimmun Rev. 2013;12:904-911.

116. Chamberlain-Banoub J, Neal JW, Mizuno M, et al. Complement membrane attack is required for endplate damage and clinical disease in passive experimental myasthenia gravis in Lewis rats. Clin Exp Immunol. 2006;146:278-286.

117. Morgan BP, Chamberlain-Banoub J, Neal JW, et al. The membrane attack pathway of complement drives pathology in passively induced experimental autoimmune myasthenia gravis in mice. Clin Exp Immunol. 2006;146:294-302.

118. Lennon VA, Seybold ME, Lindstrom JM, et al. Role of complement in the pathogenesis of experimental autoimmune myasthenia gravis. J Exp Med. 1978;147:973-983.

119. Christadoss P. C5 gene influences the development of murine myasthenia gravis. J Immunol. 1988;140:2589-2592.

120. Kaminski HJ, Kusner LL, Richmonds C, et al. Deficiency of decay accelerating factor and CD59 leads to crisis in experimental myasthenia. Exp Neurol. 2006;202:287-293.

121. Lin F, Kaminski HJ, Conti-Fine BM, et al. Markedly enhanced susceptibility to experimental autoimmune myasthenia gravis in the absence of decay-accelerating factor protection. J Clin Invest. 2002;110: 1269-1274.

122. Huda R, Tuzun E, Christadoss P. Targeting complement system to treat myasthenia gravis. Rev Neurosci. 2014;25:575-583.

123. Sun L, Xing L, Zhang GH, et al. A new method to induce myasthenia gravis models and the protective effect of soluble decay accelerating factors. Genet Mol Res. 2015;14:7782-7792.

124. Soltys J, Kusner LL, Young A, et al. Novel complement inhibitor limits severity of experimentally myasthenia gravis. Ann Neurol. 2009;65: 67-75.

125. Losen M, Stassen MH, Martinez-Martinez P, et al. Increased expression of rapsyn in muscles prevents acetylcholine receptor loss in experimental autoimmune myasthenia gravis. Brain. 2005;128:2327-2337.
126. Martinez-Martinez P, Losen M, Duimel H, et al. Overexpression of rapsyn in rat muscle increases acetylcholine receptor levels in chronic experimental autoimmune myasthenia gravis. Am J Pathol. 2007;170: 644-657.

127. O'Connell RM, Baltimore D. MicroRNAs and hematopoietic cell development. Curr Top Dev Biol. 2012;99:145-174.

128. Zhang J, Jia G, Liu Q, et al. Silencing miR-146a influences B cells and ameliorates experimental autoimmune myasthenia gravis. Immunology. 2015;144:56-67.

129. Wang YZ, Tian FF, Yan M, et al. Delivery of an miR155 inhibitor by anti-CD20 single-chain antibody into B cells reduces the acetylcholine receptor-specific autoantibodies and ameliorates experimental autoimmune myasthenia gravis. Clin Exp Immunol. 2014;176:207-221.

130. Wang J, Zheng S, Xin N, et al. Identification of novel MicroRNA signatures linked to experimental autoimmune myasthenia gravis pathogenesis: down-regulated miR-145 promotes pathogenetic Th17 cell response. J Neuroimmune Pharmacol. 2013;8:1287-1302.

131. Losen M, Martinez-Martinez P, Molenaar PC, et al. Standardization of the experimental autoimmune myasthenia gravis (EAMG) model by immunization of rats with Torpedo californica acetylcholine receptors - recommendations for methods and experimental designs. Exp Neurol. 2015;270:18-28.

132. Tuzun E, Berrih-Aknin S, Brenner T, et al. Guidelines for standard preclinical experiments in the mouse model of myasthenia gravis induced by acetylcholine receptor immunization. Exp Neurol. 2015;270:11-17.

133. Cavalcante P, Bernasconi P, Mantegazza R. Autoimmune mechanisms in myasthenia gravis. Curr Opin Neurol. 2012;25:621-629.

134. Melms A, Schalke BC, Kirchner T, et al. Thymus in myasthenia gravis. Isolation of T-lymphocyte lines specific for the nicotinic acetylcholine receptor from thymuses of myasthenic patients. J Clin Invest. 1988;81:902-908.

135. Meinl E, Klinkert WE, Wekerle $\mathrm{H}$. The thymus in myasthenia gravis. Changes typical for the human disease are absent in experimental autoimmune myasthenia gravis of the Lewis rat. Am J Pathol. 1991;139: 995-1008.

136. Gomez AM, Willcox N, Vrolix K, et al. Proteasome inhibition with bortezomib depletes plasma cells and specific autoantibody production in primary thymic cell cultures from early-onset myasthenia gravis patients. J Immunol. 2014;193:1055-1063.

137. Russel WMS, Burch RL. The Principles of Humane Experimental Technique. Special Edition UFAW. London: Methuen \& Co; 1992.

138. Ma CG, Zhang GX, Xiao BG, Link J, Olsson T, Link H. Suppression of experimental autoimmune myasthenia gravis by nasal administration of acetylcholine receptor. J Neuroimmunol. 1995;58(1):51-60.

139. Zhang JM, Jia G, Liu Q, et al. Silencing miR-146a influences B cells and ameliorates experimental autoimmune myasthenia gravis. Immunology. 2014;144:56-67.
International Journal of General Medicine

\section{Publish your work in this journal}

The International Journal of General Medicine is an international, peer-reviewed open-access journal that focuses on general and internal medicine, pathogenesis, epidemiology, diagnosis, monitoring and treatment protocols. The journal is characterized by the rapid reporting of reviews, original research and clinical studies across all disease areas.
Dovepress

A key focus is the elucidation of disease processes and management protocols resulting in improved outcomes for the patient. The manuscript management system is completely online and includes a very quick and fair peer-review system. Visit http://www.dovepress.com/ testimonials.php to read real quotes from published authors. 